Editors' Note: WriteClick correspondence this week centers on the article by Dr. Ragauskas et al., "Clinical assessment of noninvasive intracranial pressure absolute value measurement method." Dr. Liebeskind et al. bring up variability in the microanatomy of the ophthalmic artery that argues against the authors' methodology. Dr. Miller et al. disagree that extracranial ophthalmic arterial blood flow is independent of CSF, citing their own data on the subject. Authors Ragauskas et al. dispute both claims. Megan Alcauskas, MD, and Robert C. Griggs, MD

\section{CLINICAL ASSESSMENT OF NONINVASIVE INTRACRANIAL PRESSURE ABSOLUTE VALUE MEASUREMENT METHOD}

David S. Liebeskind, Los Angeles; E. Marcinkevicius, Kaunas, Lithuania; M. Pranevicius, O. Pranevicius, New York: Ragauskas et al. ${ }^{1}$ demonstrated that when external pressure is applied, the orbit tends to equilibrate flow in the ipsilateral ophthalmic artery (OA) when its level approaches intracranial pressure (ICP). The authors detected this relationship by making the OA into a "natural pair of scales, in which the intracranial segment of the OA is compressed by extracranial pressure (Pe) applied to the orbit."

Although the conclusion is interesting, there is an implicit assumption that $\mathrm{OA}$ crosses a compartmental barrier, which in this case can only be the dural boundary. Consequently, the proposition that ICP can be measured noninvasively, by merely balancing external pressures between the subdural and extradural parts of $\mathrm{OA}$, assumes that these 2 segments of the OA exist in the entire population, or at least the majority of the population. However, microanatomical studies have shown different configurations and variability, ${ }^{2,3}$ reporting that incidence of the $\mathrm{OA}$ originating from the intradural portion of the internal carotid artery ranges from $4.7 \%$ to $89.6 \%$.

The described effect is therefore unlikely as it is solely explained by transmural pressure balances across these distinct OA segments, thus leaving the underlying mechanism still unclear.

Author Response: A. Ragauskas, V. Matijosaitis, R. Zakelis, K. Petrikonis, D. Rastenyte, Kaunas, Lithuania; I. Piper, Glasgow, Scotland;
G. Daubaris, Kaunas, Lithuania: We thank Liebeskind et al. for their interest in the results of our assessment of noninvasive ICP measurement technology, which does not need patient-specific calibration. ${ }^{1}$ We respectfully disagree with the assumption that "pressure on the orbit does not balance transmural pressure in the segments of ophthalmic artery (OA)." Statistically significant evidence-based results of clini$\mathrm{cal}^{1,4}$ and healthy volunteer ${ }^{5}$ studies show that this assumption has no scientific background. Dr. Heyreh ${ }^{5}$ demonstrated that intracranial segment (IOA) of the OA is absent in $5 \%$ of humans. Our multidepth TCD technology ${ }^{1}$ with increased resolution of OA blood velocity measurements is a tool for accurate experimental identification of the anatomical structure of the IOA and of the OA physiologic reactions to ICP. ${ }^{4}$ Absolute ICP noninvasive measurements of hundreds of healthy volunteers, and neurologic and traumatic brain injury patients showed that our technology can be used on more than $96 \%$ of individuals independently of age, gender, or intracraniospinal pathology. Physiologic findings ${ }^{1,4,6}$ of OA reaction to ICP and pressure on the orbit fully support conclusions of an anatomical study, ${ }^{5}$ which showed that the intracranial course of OA may be absent in just $5 \%$ of individuals.

(C) 2013 American Academy of Neurology

1. Ragauskas A, Matijosaitis V, Zakelis R, et al. Clinical assessment of noninvasive intracranial pressure absolute value measurement method. Neurology 2012;78:1684-1691.

2. Matsumura Y, Nagashima M. Anatomical variations in the origin of the human ophthalmic artery with special reference to the cavernous sinus and surrounding meninges. Cells Tissues Organs 1999;164:112-121.

3. Huynh-Le P, Natori Y, Sasaki T. Surgical anatomy of the ophthalmic artery: its origin and proximal course. Neurosurgery 2005;57(4 suppl):236-241.

4. Ragauskas A, Bartusis L, Zakelis R, Daubaris G. Noninvasive absolute intracranial pressure value measurements during HUT/HDT tests. Cerebrovasc Dis 2012; 33(suppl 1):78.

5. Hayreh S. Orbital vascular anatomy. Eye 2006;20:1130-1144.

6. Ragauskas A, Bartusis L, Zakelis R, et al. Statistical validity of non-invasive absolute intracranial pressure value meter for evidence based medicine. Cerebrovasc Dis 2012;33(suppl 1):74.

Marijean M. Miller, Taeun Chang, Robert Keating, Craig Sable, Washington, DC: We have concerns with the article by Ragauskas et al., who assessed the 
precision of a method for noninvasive ICP measurement compared with the invasive gold standard CSF pressure measurement. ${ }^{1}$

The authors assume that extracranial OA blood flow is independent of ICP. We disagree. Both adult and pediatric work in the last decade demonstrated the effect and correlation of ICP on distal blood vessels. ${ }^{2-5}$ In 2009, we measured central retinal artery and vein blood flow velocities by spectral Doppler imaging in awake, supine children and determined the velocity of blood flow is reduced by elevated ICP. ${ }^{5}$ Our method is noninvasive and can be performed without anesthesia on children.

We also have safety concerns. Transcranial spectral Doppler imaging through bone necessitates the use of higher Doppler power than ocular Doppler imaging. The authors' diagram (figure 1) places the transcranial Doppler probe precariously close to the lens, but does not publish powers used. Their method would only be applicable in alert and cooperative adults. In addition, applying prolonged pressure to the globe can reduce central retinal artery blood flow and may result in vision loss.

\section{Author Response: A. Ragauskas, V. Matijosaitis,} R. Zakelis, K. Petrikonis, D. Rastenyte, Kaunas, Lithuania; I. Piper, Glasgow, Scotland; G. Daubaris, Kaunas, Lithuania: We thank Miller et al. for their interest in the results of our assessment of noninvasive ICP measurement technology. This method is accurate and sensitivity and specificity are much higher compared with other approaches. ${ }^{1,6,7}$

Blood flow in both segments of the OA depends on ICP, ambulatory blood pressure, heart rate, intraocular pressure, intraorbital pressure, and other factors. ${ }^{1}$ The benefit of our method is in the equilibration of ICP with Pe. The balance ICP = Pe is not dependent on influential factors. OA blood flow velocities could be very different in different patients ${ }^{1}$ but the balance ICP $=$ Pe does not depend on the OA blood flow velocity values. As a result, our method does not need a patient-specific calibration. All "correlation-based" noninvasive ICP measurement approaches cannot be used for absolute ICP value measurements because they need patient-specific calibration, which is impossible.

Our 2-depth transcranial Doppler technology complies with all safety standards. The maximum value of $\mathrm{Pe}$ is $50 \mathrm{~mm} \mathrm{Hg}$ and so $\mathrm{Pe}$ is applied to the orbit for just 90 seconds. We diagnosed vision changes after 115 snapshot ICP measurements. Experts have agreed that our technology has no influence on vision impairment.

(C) 2013 American Academy of Neurology

1. Ragauskas A, Matijosaitis V, Zakelis R, et al. Clinical assessment of noninvasive intracranial pressure absolute value measurement method. Neurology 2012;78:16841691.

2. Mitra RA, Sergott RC, Flaharty PM, et al. Optic nerve decompression improves hemodynamic parameters in papilledema. Ophthalmology 1993;100:987-997.

3. Querfurth HW, Lagreze WD, Hedges TR, Heggerick PA. Flow velocity and pulsatility of the ocular circulation in chronic intracranial hypertension. Acta Neurol Scand 2002;105:431-440.

4. Miller M, Sable C, Chang T. Spectral Doppler imaging of vessels in the optic nerve of children. J Child Neurol 2007; 22:809-811.

5. Miller MM, Chang T, Keating R, Crouch E, Sable C. Blood flow velocities are reduced in the optic nerve of children with elevated intracranial pressure. J Child Neurol 2009;24:30-35.

6. Ragauskas A, Bartusis L, Zakelis R, Daubaris G. Noninvasive absolute intracranial pressure value measurements during HUT/HDT tests. Cerebrovasc Dis 2012; 33(suppl 1):78.

7. Ragauskas A, Bartusis L, Zakelis R, et al. Statistical validity of non-invasive absolute intracranial pressure value meter for evidence based medicine. Cerebrovasc Dis 2012;33 (suppl 1):74.

\section{CORRECTION}

Migraine headache is present in the aura phase: A prospective study

In the article "Migraine headache is present in the aura phase: A prospective study" by J.M. Hansen et al. (Neurology ${ }^{\circledR}$ 2012;79:2044-2049), there is an error in the abstract. The second sentence of the Results should read "Other migraine symptoms were also frequently reported during the aura: nausea (51\%), photophobia (88\%), and phonophobia (73\%)." The authors regret the error. 


\section{Neurology}

\section{Clinical Assessment of Noninvasive Intracranial Pressure Absolute Value Measurement Method}

David S. Liebeskind, A. Ragauskas, Marijean M. Miller, et al. Neurology 2013;80;507-508

DOI 10.1212/WNL.0b013e318281bfa4

This information is current as of January 28, 2013

\section{Updated Information \&} Services

References

Permissions \& Licensing

Reprints including high resolution figures, can be found at: http://n.neurology.org/content/80/5/507.full

This article cites 13 articles, 2 of which you can access for free at: http://n.neurology.org/content/80/5/507.full\#ref-list-1

Information about reproducing this article in parts (figures,tables) or in its entirety can be found online at:

http://www.neurology.org/about/about_the_journal\#permissions

Information about ordering reprints can be found online: http://n.neurology.org/subscribers/advertise

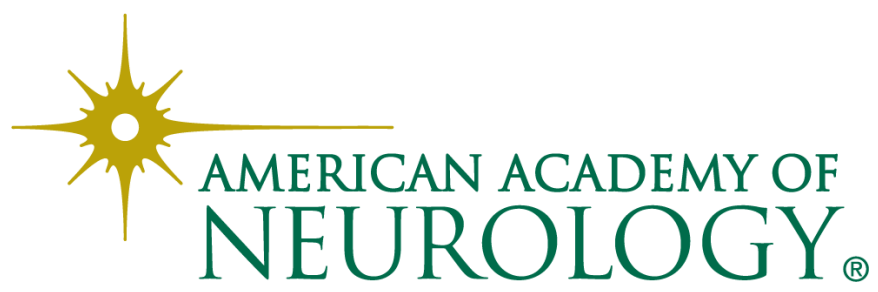

